\title{
Elimination of Amoxicillin from Hospital Wastewater Using the Cold Plasma Technique
}

\author{
Phuong Thi Thanh Nguyen', Hiep Nghia Bui², Hieu Trung Nguyen³, \\ Thien Huu Pham ${ }^{4}$, Tri Huu Nguyen ${ }^{5}$, Ha Manh Bui ${ }^{6 *}$ \\ ${ }^{1}$ Institute of Environmental Industry, Ho Chi Minh City 700000, Vietnam \\ ${ }^{2}$ Department of Environmental Engineering, Dayeh University, Changhua 51591, Taiwan \\ ${ }^{3}$ Institute of Applied Technology, Thu Dau Mot University, Thu Dau Mot City, Binh Duong Province 750000, Vietnam \\ ${ }^{4}$ Institute of Applied Materials Science - VAST, Ho Chi Minh City 700000, Vietnam \\ ${ }^{5}$ Department of Science Management, Saigon University, Ho Chi Minh City 700000, Vietnam \\ ${ }^{6}$ Department of Environmental Sciences, Saigon University, Ho Chi Minh City 700000, Vietnam
}

Received: 9 March 2021

Accepted: 17 August 2021

\begin{abstract}
In this paper, a cold plasma process was employed for the removal of amoxicillin (AM) and total organic carbon (TOC) from real hospital wastewater in Vietnam via the statistical design of a central composite design (CCD), with three factors of initial $\mathrm{pH}$, applied voltage, and reaction time, respectively. Under optimal treatment conditions of a reaction time of $36.5 \mathrm{~min}$, initial $\mathrm{pH}$ of 10.5 , and an applied voltage of $36.5 \mathrm{kV}$, a good TOC removal efficiency of $\sim 72.4 \%$ as well as most of the amoxicillin was eliminated. In addition, theoretical approaches (e.g., DFT and NBO calculations) revealed the proposed major degradation pathways of $\mathrm{AM}$ and the final mineralization to $\mathrm{H}_{2} \mathrm{O}, \mathrm{CO}_{2}, \mathrm{SO}_{4}{ }^{2-}$, and $\mathrm{NO}_{3}^{-}$. The obtained results demonstrate the potential of employing a cold plasma process for the treatment of pharmaceutical-containing wastewater.
\end{abstract}

Keywords: advanced oxidation processes, antibiotics, cold plasma, hospital wastewater

\section{Introduction}

The majority of pharmaceuticals that are introduced into the environment contaminate surface water (such as streams, lakes, and rivers), groundwater, and drinking water [1]. Most of the contaminated pharmaceuticals originate from hospital wastewater (HWW) [2], containing not only high refractory but also a high concentration of organic compounds; these compounds

e-mail: manhhakg@yahoo.com.vn, manhhakg@sgu.edu.vn adversely affect aquatic organisms and humans. Pharmaceutical residues are classified as environmental micropollutants, which have attracted research attention worldwide [3].

Penicillin or beta-lactam family are among the most widely used pesticides to treat bacterial infections. In particular, amoxicillin (AM) is well known due to its high production and worldwide distribution [4]. After first being registered by the Beecham Group in 1972, AM has become one of the most widely prescribed antibiotics. AM is classified as one of the pharmaceutical contaminants with emerging concern due to its persistence, bioaccumulation, and possible transfer to 
living organisms [5]. Approximately $0.2 \mu \mathrm{g} / \mathrm{L}$ of $\mathrm{AM}$ has been detected in surface water and wastewater [6]. González-Pérez et al. (2016) [7] have reported that AM is highly toxic to tropical freshwater Daphnia species $\left(\mathrm{LC}_{50}=0.25 \mathrm{mg} / \mathrm{L}\right)$. To control the discharge of pharmaceutical compounds from HWW, several drug industries are operating conventional effluent treatment plants based on chemical coagulation technology [8]. However, the major drawbacks of this technique include low removal efficiencies, large quantities of produced sludge, increased working areas, and long detention times. In addition, it is not considered to be economical due to high costs of large quantities of chemicals required for coagulation, floatation, and conductivity adjustment. Meanwhile, biological processes are limited to only biodegradable waste, while nanofiltration and adsorption are not only expensive technologies, but also it is not sufficient to achieve discharge limits [9]. Hence, an increasing number of studies are now being focused on advanced oxidation processes (AOPs), which utilize highly reactive species, i.e., photocatalysis [10, 11], ozone treatment [12], activated persulfate [13, 14], the electro-Fenton process [5], and an electronbeam process $[15,16]$; these processes have been verified to achieve high elimination rates of different pharmaceuticals in an aqueous solution [17]. Among the aforementioned AOP techniques, cold plasma has been reported as an effective alternative for the degradation of various contaminants, including pharmaceuticals in water [18]. The cold plasma process involves the excitation of an irradiated solution, inducing the generation of highly reactive radicals, mainly hydroxyl radicals $(\cdot \mathrm{OH})$, hydrogen radicals $(\cdot \mathrm{H})$, hydrated electrons $\left(\mathrm{e}^{-}\right)$, hydrogen peroxide $\left(\mathrm{H}_{2} \mathrm{O}_{2}\right)$, ozone $\left(\mathrm{O}_{3}\right)$, and UV light [19]. These species are capable of decomposing the target pollutant into carbon dioxide and water. Recently, cold plasma treatment has attracted considerable attention as the reactive species can be formed without the supply of chemicals, and the produced compounds are biodegradable. This technique has been considered to be effective for the treatment of effluents from several industries, including textiles [20], meat and poultry [21], pesticides [19], and pharmaceuticals [2, 22]. Although cold plasma can reduce the organic compounds in aqueous solutions, scarce literature is available on the removal of these contaminants by this technique from real HWW. Therefore, in this study, effects of initial $\mathrm{pH}$, applied voltage, and reaction time on the removal of the total organic carbon (TOC) and AM in real HWW by the cold plasma technique are investigated. In addition, optimization conditions are determined by the central composite design (CCD) method. Furthermore, the degradation mechanism based on theoretical calculations of the treatment process was evaluated.

\section{Methodology}

\section{Wastewater and Chemicals}

All chemicals, i.e., AM $\left(\mathrm{C}_{16} \mathrm{H}_{19} \mathrm{~N}_{3} \mathrm{O}_{5} \mathrm{~S}\right)$, sulfuric acid $\left(\mathrm{H}_{2} \mathrm{SO}_{4}\right)$, sodium hydroxide $(\mathrm{NaOH})$, methanol $\left(\mathrm{CH}_{3} \mathrm{OH}\right)$, acetonitrile $\left(\mathrm{C}_{2} \mathrm{H}_{3} \mathrm{~N}\right)$, ethyl acetate $\left(\mathrm{C}_{4} \mathrm{H}_{8} \mathrm{O}_{2}\right)$, an ammonium hydroxide solution $\left(\mathrm{NH}_{4} \mathrm{OH}\right)$, acetic acid $\left(\mathrm{CH}_{3} \mathrm{COOH}\right)$, and formic acid $(\mathrm{HCOOH})$, were purchased from Sigma-Aldrich (St. Louis, MO, USA), and solutions were prepared using deionized water with a resistivity of no less than $18.2 \mathrm{M} \Omega / \mathrm{cm}$. The wastewater was collected from an equalization tank at a hospital treatment plant located in Ho Chi Minh City, Vietnam. The effluent characteristics were as follows: initial $\mathrm{pH}$ of $7.2-7.8$, TOC of $118.6-128.9 \mathrm{mg} / \mathrm{L}$, total nitrogen $(\mathrm{TN})$ of $28.5-38.3 \mathrm{mg} / \mathrm{L}$, ammonium $\left(\mathrm{NH}^{4+}-\mathrm{N}\right)$ of $16.7-21.5 \mathrm{mg} / \mathrm{L}$, and AM of 27.8 - $31.6 \mathrm{mg} / \mathrm{L}$. The chemicals, solutions, and wastewater were kept in the dark and stored at $4^{\circ} \mathrm{C}$.

\section{Experimental Design and Procedure}

The plasma reactor is a 5-mm-thick plastic (plexiglass) cylindrical chamber with an inner diameter of $14 \mathrm{~cm}$ and a height of $30 \mathrm{~cm}$; this chamber is capable of retaining $1500 \mathrm{~mL}$ of the effluent, including other instruments such as pumps, valves and electrodes, etc., which has been described in detail in our previous study [2]. The CCD approach with three controllable factors was considered: initial $\mathrm{pH}$, applied voltage, and reaction time. Three levels of these factors were selected for the experimental design with 20 experiments (Table 1).

The design was created using the MINITAB software, and the significant evaluation based on analysis of variance (ANOVA) and coefficient of determination $\left(\mathrm{R}^{2}\right)$. To optimize the removal efficiency of treatment processes (i.e., TOC and AM removal efficiencies), initial $\mathrm{pH}(8-12)$, applied voltage (15-35 kV), and reaction time (10-20 $\mathrm{min})$ were evaluated on the basis of previous investigations [2].

Table 1 . The coded and uncoded levels of independent variables in this study.

\begin{tabular}{|c|c|c|c|c|c|c|}
\hline \multirow{2}{*}{ Parameters } & \multirow{2}{*}{ Symbol } & & \multicolumn{3}{|c|}{ Level } & \\
\cline { 3 - 7 } & & $-\alpha$ & (Low) -1 & (Center) 0 & $($ High) 1 & $+\alpha$ \\
\hline Initial $\mathrm{pH}$ & $\mathrm{X}_{1}$ & 6.6 & 8 & 10 & 12 & 13.4 \\
\hline Applied voltage (kV) & $\mathrm{X}_{2}$ & 26.6 & 30 & 35 & 40 & 43.4 \\
\hline Reaction time (min) & $\mathrm{X}_{3}$ & 21.6 & 25 & 30 & 35 & 38.4 \\
\hline
\end{tabular}


In each run, after the addition of the $\mathrm{pH}$-adjusted wastewater to the reaction chamber, the bottom two valves and cooling tower were locked. Then, at a constant flow rate of $4 \mathrm{~L} / \mathrm{min}$, air was delivered into the chamber, the power supply was turned on, and the applied voltage was adjusted to the desired levels during a set of reaction time. Subsequently, aliquots of the treated wastewater were taken, and the bottom discharge was analyzed.

\section{Calculation Methods}

In this study, geometrical and electronic structures of $\mathrm{AM}$ and its intermediates were optimized by density function theory (DFT) with the B3LYP/6-311++G(d,p) basis set. These optimized structures were used as input data for natural bond orbital (NBO) calculations. All calculations were performed using Gaussian software with already built-in NBO. In addition, these calculations were based on the solution model of the polarizable continuum model (PCM) with aqueous solvents.

\section{Analysis Method}

AM was analyzed by HPLC-UV (Shimadzu Model 20AT) using an automatic injector. A Phenomenex Luna reverse-phase chromatography column $(250 \times 4.6 \mathrm{~mm}$, $3.5 \mu \mathrm{m})$ packed with a C18 stationary phase (particle size of $5 \mu \mathrm{m}$ ) was used. A $96 \%$ buffered solution (phosphate at $\mathrm{pH}=3.6$ ) with $6 \%$ acetonitrile in the isocratic mode at a flow rate of $1 \mathrm{~mL} / \mathrm{min}$ was used as the mobile phase to separate AM and its by-products. The oven temperature was maintained at $30^{\circ} \mathrm{C}$.
The injected volume was $10 \mu \mathrm{L}$, and the wavelength was maintained constant at $230 \mathrm{~nm}$. Each sample was analyzed in triplicate to verify the stability of the system. TOC was analyzed using a TOC Vcph/cpn instrument (Shimadzu, Japan). $\mathrm{pH}$ and $\mathrm{NH}_{4}^{+}-\mathrm{N}$ were evaluated according to the Standard Methods for the Examination of Water and Wastewater [23]. Statistical analysis was performed using the Minitab 18.1 version (Minitab Inc, USA), and a $p$-value $<0.05$ was considered to be significant.

\section{Results and Discussion}

\section{Model Fitting and Validation}

Table 2 summarizes the ANOVA results of regression parameters of the predicted quadratic response, as well as other statistical factors. Statistical results observed that most of the analyzed interactions between the three variables (i.e., initial $\mathrm{pH}$, applied voltage, and reaction time, respectively) do not exhibit significant effects on the removal efficiencies of TOC and AM from wastewater, except for the interaction between the initial $\mathrm{pH}$ and reaction time in case of AM removal and between the applied voltage and reaction time in case of TOC removal, while all other linear and quadratic regression models exhibit significant effects $(<0.05)$ on AM and TOC removal efficiencies. This result can be confirmed by the Pareto chart with 95\% confidence (Fig. 1). Hence, the model for forecasting the removal of AM and TOC using cold plasma is described by second-order polynomial Equations (1) and (2):

Table 2. Analysis of variance (ANOVA) for AM and TOC removal efficiencies (\%).

\begin{tabular}{|c|c|c|c|c|c|c|c|c|}
\hline Factors & Source & $\mathrm{DF}$ & Coef & $\mathrm{SS}$ & $\mathrm{MS}$ & F-Value & $P$-Value & Notice \\
\hline \multirow{5}{*}{ Model } & 9 & -724.7 & 2584.76 & 287.2 & 102.89 & $<0.001$ & Significant \\
\cline { 2 - 9 } & $\mathrm{X}_{1}$ - Initial $\mathrm{pH}$ & 1 & 6.81 & 31.9 & 31.9 & 11.43 & 0.007 & Significant \\
\cline { 2 - 9 } & $\mathrm{X}_{2}$ - Applied voltage & 1 & 21.78 & 124.43 & 124.43 & 44.58 & $<0.001$ & Significant \\
\cline { 2 - 9 } & $\mathrm{X}_{3}$ - Reaction time & 1 & 25.38 & 153.61 & 153.61 & 55.03 & $<0.001$ & Significant \\
\cline { 2 - 9 } & $\mathrm{X}_{1}^{2}$ & 1 & -0.878 & 177.93 & 177.93 & 63.75 & $<0.001$ & Significant \\
\cline { 2 - 9 } & $\mathrm{X}_{2}^{2}$ & 1 & -0.339 & 1037.49 & 1037.49 & 371.68 & $<0.001$ & Significant \\
\cline { 2 - 9 } & $\mathrm{X}_{3}^{2}$ & 1 & -0.373 & 1250.15 & 1250.15 & 447.87 & $<0.001$ & Significant \\
\cline { 2 - 9 } & $\mathrm{X}_{1} \mathrm{X}_{2}$ & 1 & 0.395 & 124.5 & 124.5 & 44.6 & $<0.001$ & Significant \\
\cline { 2 - 9 } & $\mathrm{X}_{1} \mathrm{X}_{3}$ & 1 & -0.0076 & 4.65 & 4.65 & 1.67 & 0.226 & Not significant \\
\cline { 2 - 9 } & $\mathrm{X}_{2} \mathrm{X}_{3}$ & 1 & -0.046 & 10.35 & 10.35 & 3.71 & 0.083 & Not significant \\
\cline { 2 - 9 } & Lack-of-Fit & 5 & & 17.69 & 3.54 & 1.73 & 0.281 & Not significant \\
\hline
\end{tabular}


Table 2. Continued.

\begin{tabular}{|c|c|c|c|c|c|c|c|c|}
\hline Factors & Source & DF & Coef & SS & MS & F-Value & $P$-Value & Notice \\
\hline \multirow{5}{*}{ Model } & 9 & -527.3 & 2039.2 & 226.58 & 38.01 & $<0.001$ & Significant \\
\cline { 2 - 10 } & $\mathrm{X}_{1}$ - Initial pH & 1 & 27.08 & 133.85 & 133.85 & 22.45 & 0.001 & Significant \\
\cline { 2 - 9 } & $\mathrm{X}_{2}$ - Applied voltage & 1 & 9.49 & 109.41 & 109.41 & 18.35 & 0.002 & Significant \\
\cline { 2 - 9 } & $\mathrm{X}_{3}$ - Reaction time & 1 & 17.56 & 247.72 & 247.72 & 41.55 & $<0.001$ & Significant \\
\cline { 2 - 9 } & $\mathrm{X}_{1}{ }^{2}$ & 1 & -1.078 & 268.18 & 268.18 & 44.98 & $<0.001$ & Significant \\
\cline { 2 - 9 } & $\mathrm{X}_{2}{ }^{2}$ & 1 & -0.148 & 197.52 & 197.52 & 33.13 & $<0.001$ & Significant \\
\cline { 2 - 9 } & $\mathrm{X}_{3}{ }^{2}$ & 1 & -0.362 & 1181.61 & 1181.61 & 198.2 & $<0.001$ & Significant \\
\cline { 2 - 9 } & $\mathrm{X}_{1} \mathrm{X}_{2}$ & 1 & -0.199 & 31.76 & 31.76 & 5.33 & 0.044 & Not significant \\
\cline { 2 - 9 } & $\mathrm{X}_{1} \mathrm{X}_{3}$ & 1 & 0.101 & 8.16 & 8.16 & 1.37 & 0.269 & Not significant \\
\cline { 2 - 9 } & $\mathrm{X}_{2} \mathrm{X}_{3}$ & 1 & 0.115 & 65.67 & 65.67 & 11.01 & 0.008 & Significant \\
\cline { 2 - 9 } & Lack-of-Fit & 5 & & 47.1 & 9.42 & 3.76 & 0.086 & Not significant \\
\cline { 2 - 8 } & Pure error & 5 & & 12.52 & 2.5 & & & \\
\hline
\end{tabular}

$\mathrm{Y}_{\mathrm{AM}}=6.81 \mathrm{X}_{1}+21.78 \mathrm{X}_{2}+25.38 \mathrm{X}_{3}-0.878 \mathrm{X}_{1}^{2}$
$-0.339 \mathrm{X}_{2}^{2}-0.373 \mathrm{X}_{3}^{2}+0.395 \mathrm{X}_{1} \mathrm{X}_{2}-724.7$

$\mathrm{Y}_{\mathrm{TOC}}=27.08 \mathrm{X}_{1}+9.49 \mathrm{X}_{2}+17.56 \mathrm{X}_{3}-1.078 \mathrm{X}_{1}{ }^{2}$

$-0.148 \mathrm{X}_{2}^{2}-0.362 \mathrm{X}_{3}^{2}+0.115 \mathrm{X}_{2} \mathrm{X}_{3}-527.3$

The positive coefficient values for all linear in both equations indicates that the increase in the three factors (i.e., initial $\mathrm{pH}$, applied voltage, and reaction time, respectively) leads to the increase in the removal efficiencies, whereas the negative coefficient of quadratic indicates that the increase in the square of all three factors leads to the decrease in removal efficiencies. These results are consistent with those reported in previous studies [2, 22, 24]. The model $\mathrm{F}$ values for $\mathrm{AM}$ and TOC removal were 102.89 and 38.01, respectively, indicating that the model is sufficiently significant for the regression analysis between response and variable effects.

Model fitting was verified by determining the regression coefficient $\left(\mathrm{R}^{2}\right) \cdot R_{A M}^{2}$ and $R_{T O C}^{2}$ values of 0.9893 and 0.9716 indicated that the models cannot explain only $1.07-2.84 \%$ variation of the mean or that the models exhibit satisfactory adjustment of the quadratic models to the experimental data [25]. Moreover, the lack-of-fit for the removal of AM and TOC was non-significant (P-values $=0.281$ and $=0.086)$, confirming that the obtained model exhibits a good fit [26].
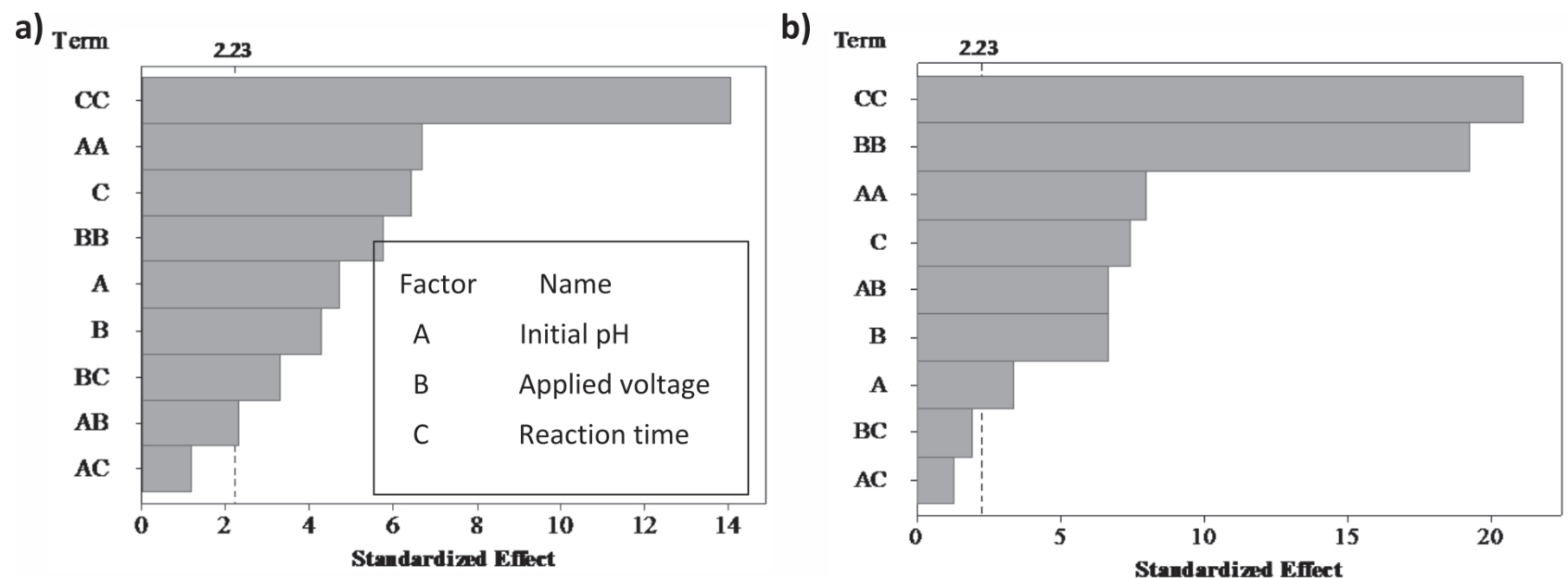

Fig. 1. Pareto chart for the analysis of the experimental data obtained for the removal of a) TOC and b) AM from HWW by the cold plasma technique with $95 \%$ confidence 
Table 3. Matrix for the CCD experiment and the corresponding experimental data.

\begin{tabular}{|c|c|c|c|c|c|c|c|c|c|}
\hline \multirow{2}{*}{ Run } & \multirow{2}{*}{ Initial $\mathrm{pH}$} & \multirow{2}{*}{$\begin{array}{l}\text { Applied voltage } \\
\qquad(\mathrm{kV})\end{array}$} & \multirow{2}{*}{$\begin{array}{l}\text { Reaction time } \\
\qquad(\min )\end{array}$} & \multicolumn{3}{|c|}{ AM removal (\%) } & \multicolumn{3}{|c|}{ TOC removal (\%) } \\
\hline & & & & Actual & Predicted & Residuals & Actual & Predicted & Residuals \\
\hline 1 & 12.0 & 40.0 & 25.0 & 82.40 & 81.44 & 0.96 & 48.80 & 46.81 & 1.99 \\
\hline 2 & 10.0 & 35.0 & 21.6 & 64.80 & 63.73 & 1.07 & 32.41 & 35.27 & -2.86 \\
\hline 3 & 10.0 & 35.0 & 30.0 & 94.94 & 95.71 & -0.77 & 68.70 & 68.05 & 0.65 \\
\hline 4 & 13.4 & 35.0 & 30.0 & 87.50 & 88.34 & -0.84 & 61.00 & 61.11 & -0.11 \\
\hline 5 & 10.0 & 35.0 & 30.0 & 94.12 & 95.71 & -1.59 & 67.12 & 68.05 & -0.93 \\
\hline 6 & 12.0 & 30.0 & 35.0 & 73.10 & 72.69 & 0.41 & 53.30 & 55.67 & -2.37 \\
\hline 7 & 8.0 & 30.0 & 25.0 & 67.34 & 68.54 & -1.20 & 42.58 & 42.64 & -0.06 \\
\hline 8 & 10.0 & 26.6 & 30.0 & 68.37 & 66.64 & 1.73 & 55.14 & 52.82 & 2.32 \\
\hline 9 & 12.0 & 30.0 & 25.0 & 64.23 & 65.23 & -1.00 & 51.33 & 50.87 & 0.46 \\
\hline 10 & 10.0 & 35.0 & 30.0 & 97.25 & 95.71 & 1.54 & 66.95 & 68.05 & -1.10 \\
\hline 11 & 10.0 & 43.4 & 30.0 & 76.22 & 76.79 & -0.57 & 59.62 & 62.34 & -2.72 \\
\hline 12 & 10.0 & 35.0 & 30.0 & 94.68 & 95.71 & -1.03 & 70.60 & 68.05 & 2.55 \\
\hline 13 & 10.0 & 35.0 & 30.0 & 97.61 & 95.71 & 1.90 & 68.70 & 68.05 & 0.65 \\
\hline 14 & 8.0 & 40.0 & 25.0 & 67.73 & 68.96 & -1.23 & 49.21 & 46.56 & 2.65 \\
\hline 15 & 10.0 & 35.0 & 30.0 & 95.46 & 95.71 & -0.25 & 66.29 & 68.05 & -1.76 \\
\hline 16 & 6.6 & 35.0 & 30.0 & 85.21 & 83.20 & 2.01 & 50.30 & 50.58 & -0.28 \\
\hline 17 & 8.0 & 40.0 & 35.0 & 75.10 & 74.92 & 0.18 & 58.60 & 58.78 & -0.18 \\
\hline 18 & 12.0 & 40.0 & 35.0 & 84.72 & 84.34 & 0.38 & 63.42 & 63.08 & 0.34 \\
\hline 19 & 8.0 & 30.0 & 35.0 & 77.26 & 79.05 & -1.79 & 41.70 & 43.41 & -1.71 \\
\hline 20 & 10.0 & 35.0 & 38.4 & 75.10 & 75.01 & 0.09 & 52.07 & 49.60 & 2.47 \\
\hline
\end{tabular}

\section{Effects of Operating Parameters}

Table 3 summarizes a design matrix containing coded and actual values of the three process parameters, the experimental and predicted removal percentages of $\mathrm{AM}$ and TOC with the residuals. Based on variations in the levels of the three process parameters, the experimental results revealed substantial differences in the removal percentages of AM and TOC. The removal percentage of AM ranged from $64.23 \%$ to $97.61 \%$, while that of TOC ranged from $32.41 \%$ to $70.6 \%$. The highest removal percentages of AM and TOC were achieved in run numbers 30 and 31 under an applied voltage of $35 \mathrm{kV}$, an initial $\mathrm{pH}$ of 10 , and a reaction time of $30 \mathrm{~min}$. On the other hand, the minimum removal percentages of AM and TOC were observed in run numbers 9 (an applied voltage of $30 \mathrm{kV}$, an initial $\mathrm{pH}$ of 12 , and a reaction time of $25 \mathrm{~min}$ ) and 2 (an applied voltage of $35 \mathrm{kV}$, an initial $\mathrm{pH}$ of 10 , and a reaction time of $21.6 \mathrm{~min}$ ). The decrease in the removal efficiencies in the two experiments may be related to a low reaction time or applied voltage $[22,24]$.

The effect of the three operating parameters on TOC and AM removal efficiencies was determined, and the results were illustrated as contour plots. Fig. 2 shows the combined effect of initial $\mathrm{pH}$ and applied voltage.

Notably, the percentage removal of AM and TOC increased with the increase in the initial $\mathrm{pH}$ from 8 to 13.5 as well as with the increase in the applied voltage from 31 to $40 \mathrm{kV}$. The further increase in the $\mathrm{pH}$ or applied voltage led to the decrease in removal efficiencies. The increase in the removal efficiency in a $\mathrm{pH}$ range of 8 to 13.5 was attributed to the reduction in the $\cdot \mathrm{OH}$ redox potential according to the Nernst equation [2]. This result indicated that an increased amount of $\cdot \mathrm{OH}$ can be formed at a high $\mathrm{pH}$ value at the same applied voltage and reaction time. Panorel et al. have also reported a high treatment capacity of cold plasma under alkaline conditions [27]. They stated that the energy consumption efficiency 

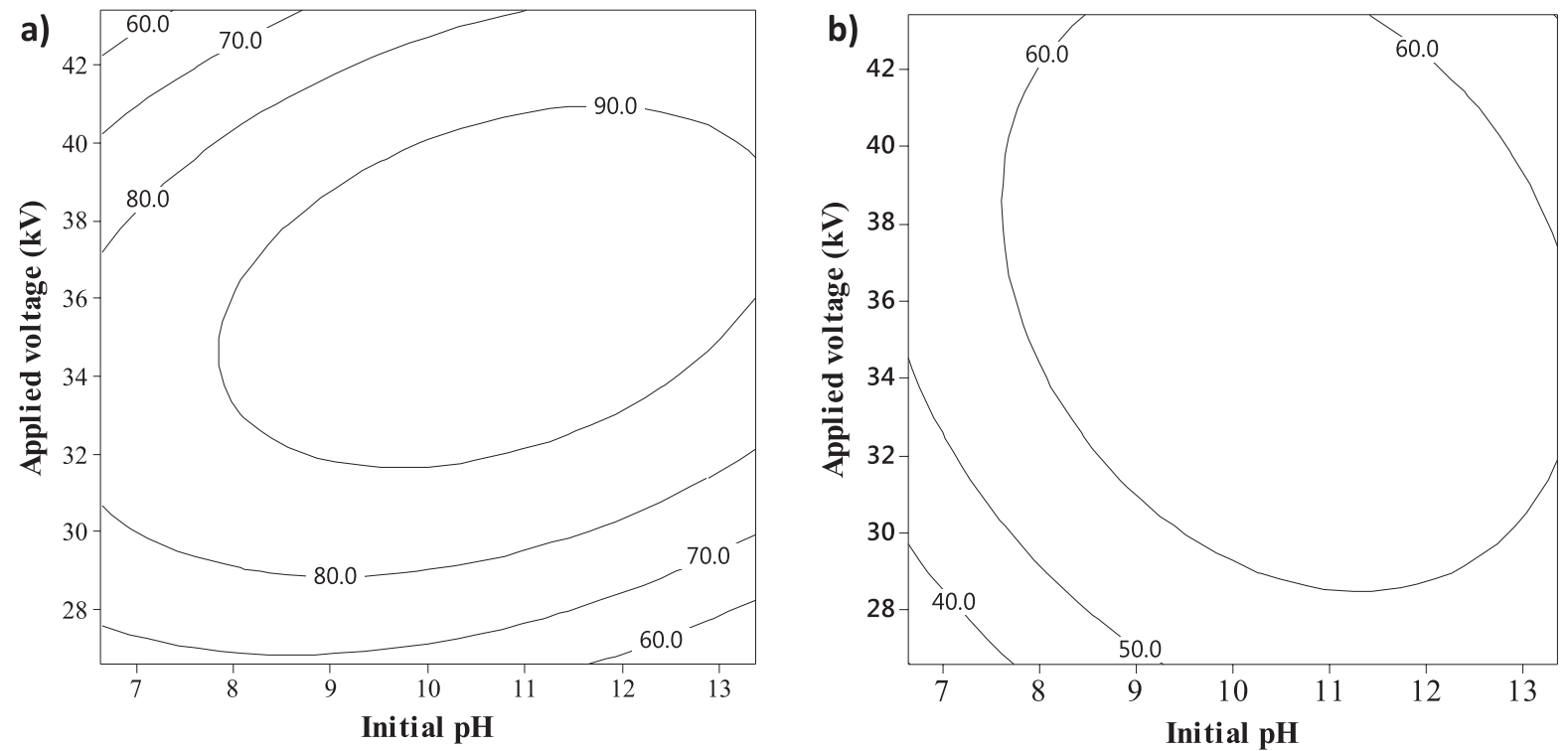

Fig. 2. Contour plots of initial $\mathrm{pH}$ and applied voltage on percentage removal of a) AM and b) TOC at a reaction time of 30 min.

for the removal of paracetamol from an aqueous solution significantly increases under alkaline conditions (52 $\mathrm{g} / \mathrm{kWh})$ in comparison with that under acidic conditions $(28 \mathrm{~g} / \mathrm{kWh})$. A similar increase trend in AM removal was observed at an applied voltage in the range of 31 to $40 \mathrm{kV}(>90 \%)$ or 28 to $42 \mathrm{kV}$ in case of TOC $(>60 \%)$. Owing to the application of a high applied voltage, an increased number of reactive species can be generated, which can accelerate the removal efficiency. Sarangapani et al. also reported that with a considerable increase in the applied voltage, the removal efficiency increases [22]; the authors have reported that with the increase in the voltage from 70 to $80 \mathrm{kV}$, the removal of ciprofloxacin increases from $75 \%$ to $89 \%$.

Fig. 3 shows the combined effect of the reaction time and initial $\mathrm{pH}$ : in the initial $\mathrm{pH}$ range of slightly to high alkaline conditions ( $\mathrm{pH} 8-13$ ) for a given reaction time (28-35 min), the highest efficiency for the percentage removal of AM and TOC was observed. Moreover, with the further increase in the initial $\mathrm{pH}$ and reaction time, the percentage removal of AM or TOC did not exhibit any significant improvement, possibly related to the formation of various radicals or oxidants in the plasma process with the increase in the reaction time as expressed in the following Equation (3) [2]:

$$
\mathrm{H}_{2} \mathrm{O} \rightarrow \cdot \mathrm{OH}+\mathrm{e}^{-}+\mathrm{H} \cdot+\mathrm{H}_{2} \mathrm{O}_{2}+\mathrm{H}_{3} \mathrm{O}^{+}+\mathrm{O}_{3}+\mathrm{UV}
$$

The reaction time also favorably affected the degradation of AM or TOC as shown in Equations (1) and (2). First, the increase in the reaction time
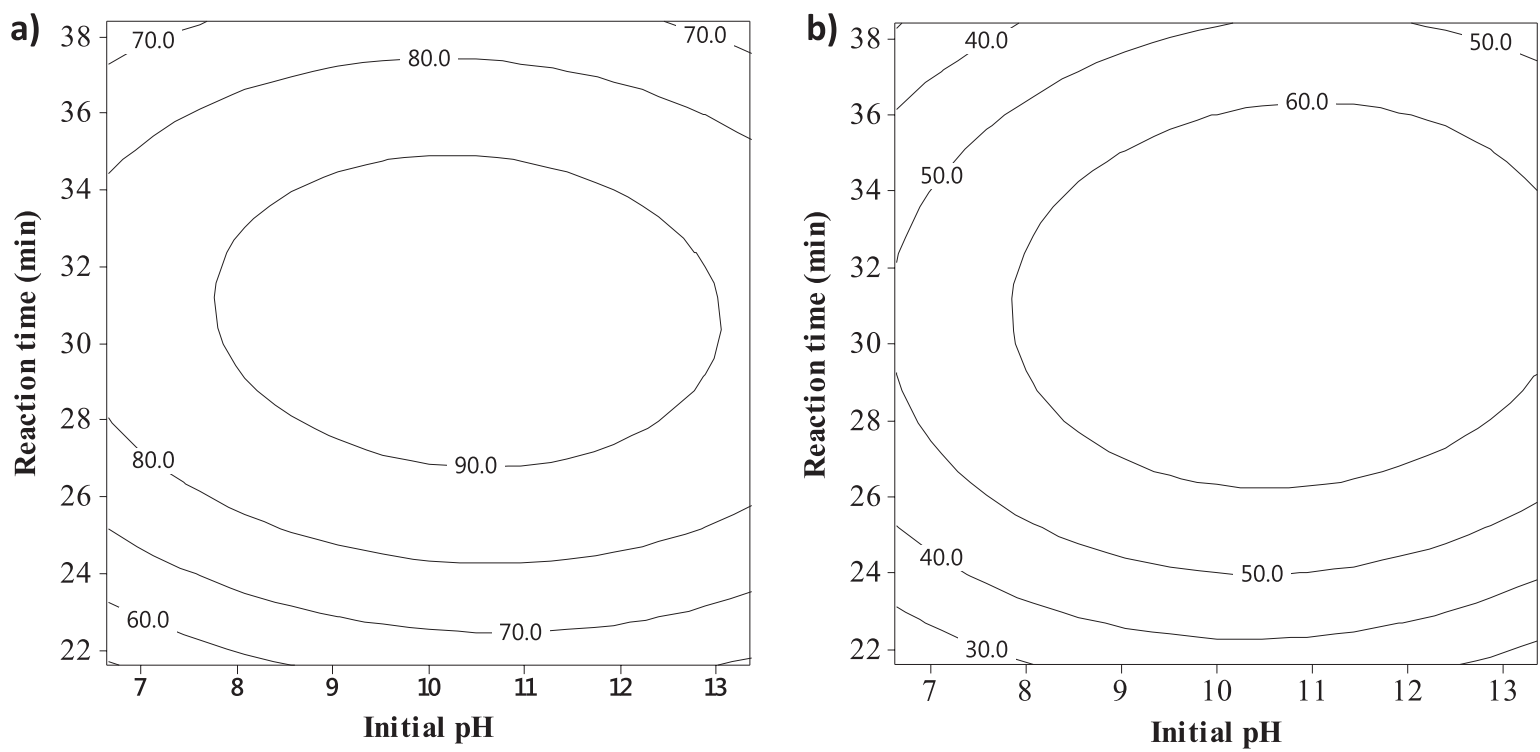

Fig. 3. Contour plots of initial $\mathrm{pH}$ and reaction time on the percentage removal of a) AM and b) TOC under an applied voltage of $35 \mathrm{kV}$. 

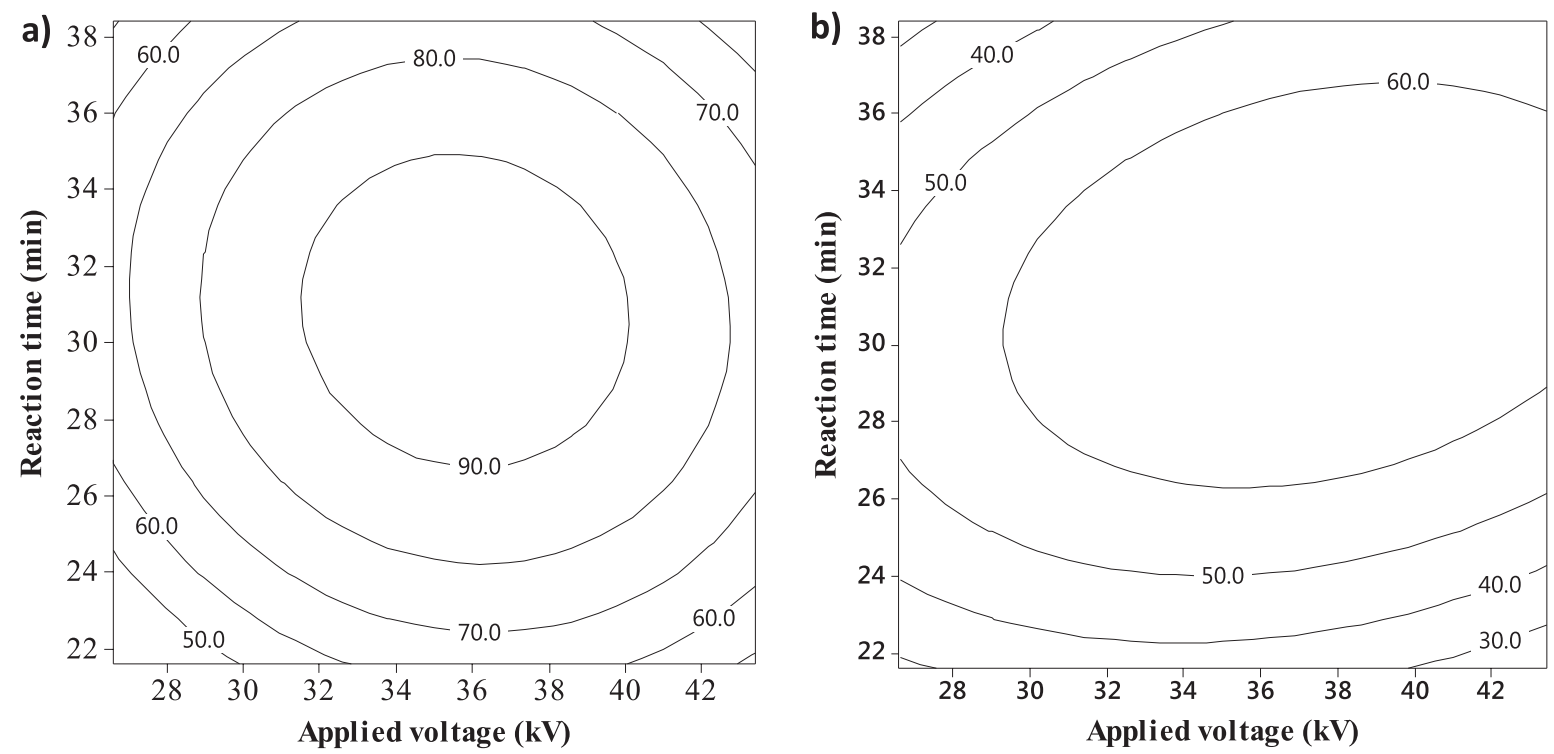

Fig. 4. Contour plots of the applied voltage and reaction time on the percentage removal of a) AM and b) TOC at an initial $\mathrm{pH}$ of $35 \mathrm{Kv}$.

is hypothesized to accelerate oxidation, where $\mathrm{AM}$ is rapidly degraded due to the formation of oxidants (mostly $\cdot \mathrm{OH}$ as shown in Equation (3)). However, with the further increase in the reaction time, the number of by-products of AM or other contaminants in the HWW increased, which compete with the mother or AM contaminant; hence, the removal efficiency decreases. The observation are in agreement with that reported by Liu et al. (2018) [28], where the authors reported that the degradation of $10 \mathrm{mg} / \mathrm{L}$ of aniline can reach $80 \%$ at $40 \mathrm{~min}$, and with the further increase in the reaction time, the degradation efficiency is only $\sim 82 \%$. Moreover, with the further increase in the reaction time, as optimal degradation is achieved, removal efficiency is not improved.

The contour plots (Fig. 4) illustrate the simultaneous effect of the applied voltage and reaction time on AM and TOC removal while simultaneously maintaining the initial $\mathrm{pH}$ level constant at 10 . Similar to previous results, the removal percentages of AM (Fig. 4a) and TOC (Fig. 4a) increase with the increase in the reaction time (28-35 $\mathrm{min})$ and applied voltage $(31-40 \mathrm{kV})$, while in case of the out of the range values, the percentage removal for TOC and AM decreases.

These findings are in agreement with those reported in previous studies [18, 24, 28]; these investigations state that at an appropriate applied voltage and reaction time, oxidant generation not only increases but also temperature is accelerated during the plasma process, leading to the reduction of a high concentration of pollutants.

\section{Optimization Process}

From the model, the optimization of the cold plasma treatment was achieved in terms of the highest AM and TOC removal efficiencies. Optimization revealed that at an applied voltage of $36.5 \mathrm{kV}$, a reaction time of $31 \mathrm{~min}$, and at initial $\mathrm{pH}$ of 10.5 , the maximum removal capacities of TOC and AM were 69.68\% and $96.52 \%$, with a desirability function of 0.706 (Fig. 5). Two additional experiments were performed to verify the optimum results. The average TOC and AM removal values obtained from experiment were $72.41 \%$ and $98.13 \%$, which were in good agreement with the predicted response values.

\section{Proposed Degradation Mechanisms of Amoxicillin by Theoretical Calculations}

As shown in Equation (3), under cold-plasma irradiation, $\cdot \mathrm{OH}, \mathrm{O}_{3}$, and $\mathrm{H}_{2} \mathrm{O}_{2}$ were the strong oxidizing agents produced in an aqueous medium, which were responsible for the breakdown of organic pollutants such as AM. Typically, in this case, AM served as a reducing agent, and it donated electrons to oxidizing agents. Therefore, the decomposition of AM under cold-plasma irradiation in an aqueous medium is essentially a redox reaction between the above oxidizing agents and the pollutant. In theoretical chemistry, this reaction is the exchange of electrons between the lowest unoccupied molecular orbitals (LUMO) of the oxidizing agent and the highest occupied molecular orbitals (HOMO) of the reducing agent. Therefore, the oxidizing agent preferentially attacks the site with a high electron density provided that the energy level of this electron is the closest to that of the LUMO of the oxidizing agent. To solve the problem of finding the active site on the AM molecule, which is difficult in the case of molecular orbital theory due to the distribution of electrons throughout the molecule, the localized orbital theory has been specifically employed to calculate the energy of natural bond orbitals (NBO). However, these NBO calculations must 


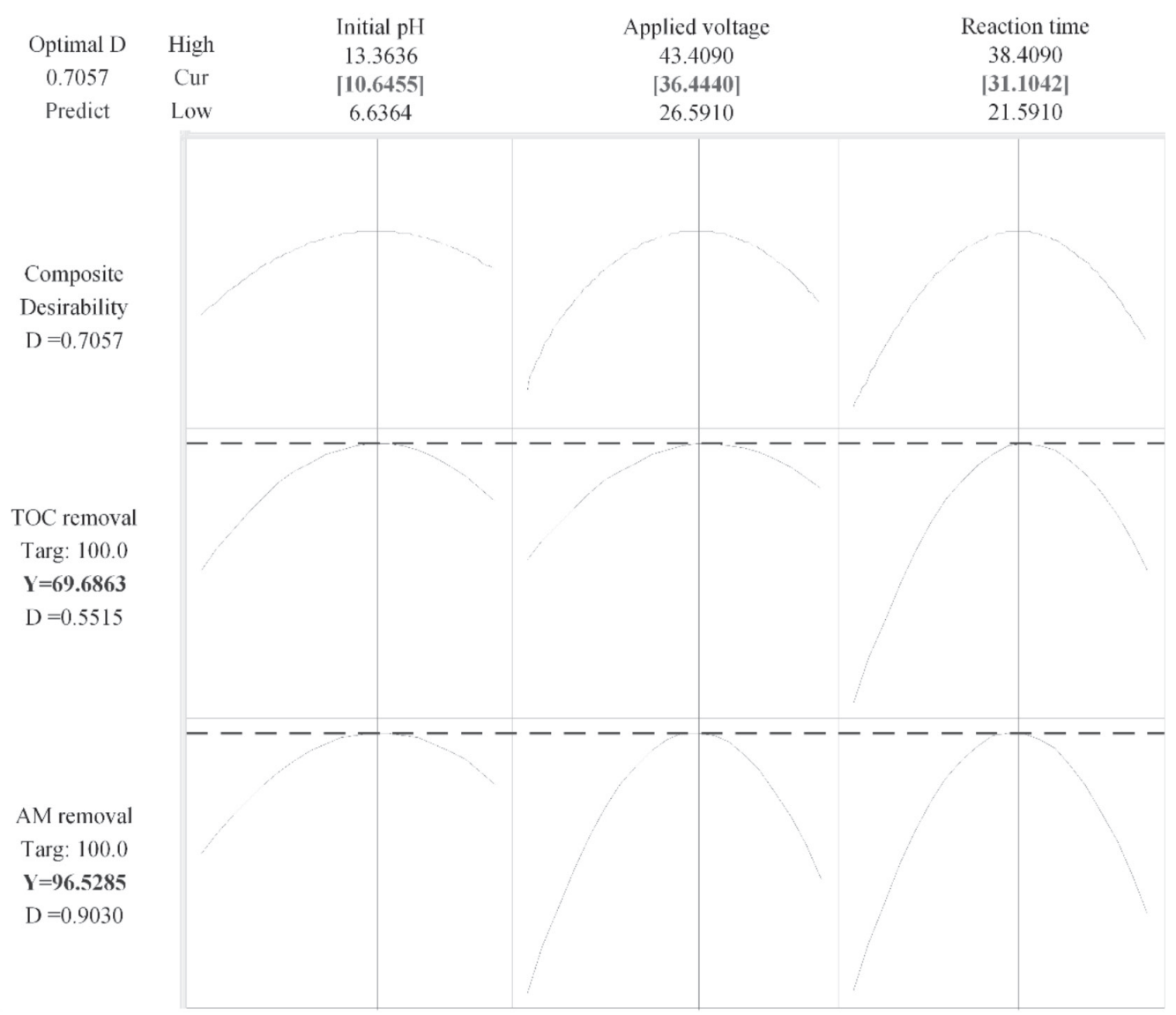

Fig. 5. Response optimization plot of the maximum AM and TOC removal efficiencies.

be based on the structure of amoxicillin optimized by density function theory (DFT) with the $6-311++\mathrm{G}(\mathrm{d}, \mathrm{p})$ basis set in an aqueous solution model (polarizable continuum model, PCM). Some DFT calculations of AM have been reported previously [29-31]. However, Anchique et al. (2021) [29] and Bebu et al. (2011) [30] have only focused on the adsorption mechanism of AM, while Gao et al. (2020) [31] have only investigated B3LYP/6-311G(d,p), natural population analysis (NPA) charges, and the electronic density as the driving force mechanism. In fact, the HOMO and LUMO are the main causes of the problem regarding the attack mechanism and decomposition of a substance in the presence of an oxidizing agent.

The highest occupied NBO in AM was located at atomic position S24 (Fig. 6, Table 4), with an energy of $-6.94 \mathrm{eV}$. Therefore, this S24 atom site is oxidized first, and one of the two single bonds of S24 with the two $\mathrm{C}$ atoms is broken to afford intermediate AM1. The highest occupied bonding NBO C6-C11 with an

Table 4. The highest occupied NBO orbitals of amoxicillin and its intermediates.

\begin{tabular}{|c|c|c|c|c|}
\hline No. & Molecule & Highest occupied NBO orbital & NBO type & Energy (eV) \\
\hline 1 & Amoxicillin & S24 & Lone pair & -6.94 \\
\hline 2 & AM1 & C6-C11 & Bonding & -7.03 \\
\hline 3 & AM2 & C5-C11 & Bonding & -7.17 \\
\hline 4 & AM3 & C5-C11 & Lone pair & -7.32 \\
\hline 5 & AM4 & N20 & Lone pair & -7.63 \\
\hline 6 & AM6 & N11 & Lone pair & -7.66 \\
\hline 7 & AM7 & O22 & Lone pair & -7.87 \\
\hline 8 & AM8 & N24 & Oone pair & -7.87 \\
\hline 9 & AM10 & & & \\
\hline
\end{tabular}




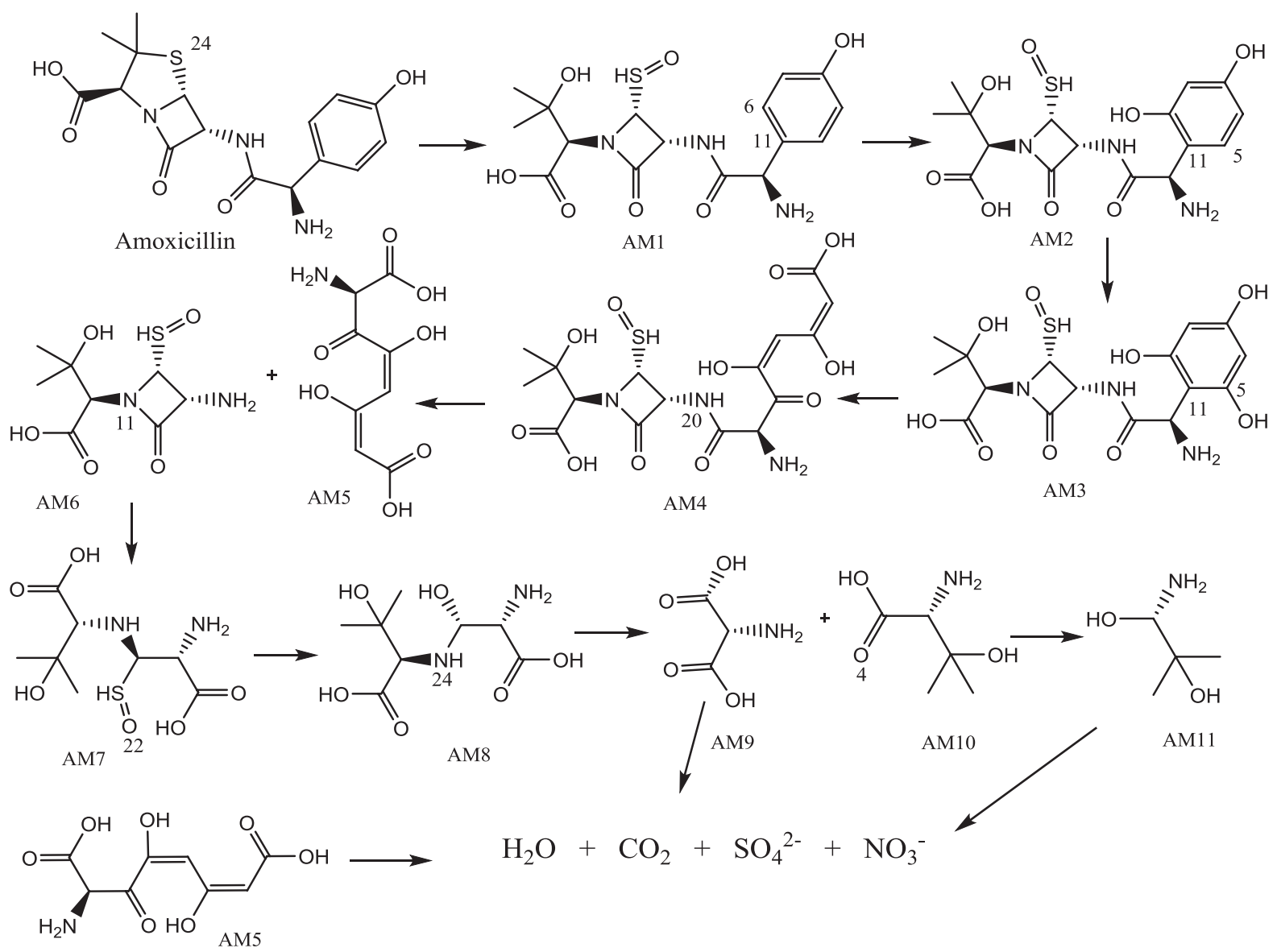

Fig. 6. Major degradation pathways of amoxicillin as proposed by DFT and NBO calculations.

energy of $-7.03 \mathrm{eV}$ is oxidized by the attachment of the -OH group to the $\mathrm{C} 6$ site. Similarly, the $-\mathrm{OH}$ group is then attached to the $\mathrm{C} 5$ position of the AM2 molecule. In the AM2 molecule, the highest NBO is still located at the $\mathrm{C} 5-\mathrm{C} 11$ bond, and oxidation continues by breaking this bond to afford the AM4 molecule. The AM4 molecule with the highest NBO at N20 is oxidized to break the $\mathrm{C}-\mathrm{N}$ bond to form AM5 and AM6 molecules. Similarly, molecule AM6 also cleaves the $\mathrm{C}-\mathrm{N}$ bond to form AM7 molecule. The $\mathrm{SH}=\mathrm{O}$ group of the AM7 molecule is further oxidized to produce $\mathrm{SO}_{4}{ }^{2-}$ and $\mathrm{AM} 8$ molecules. The $\mathrm{N} 24$ position of the AM8 molecule is the highest occupied lone pair; hence, the $\mathrm{N}-\mathrm{C}$ bond is broken to form two molecules of AM9 and AM10. Simple molecules containing a high amount of oxygen are oxidized till the end to form simple inorganic minerals such as $\mathrm{H}_{2} \mathrm{O}, \mathrm{CO}_{2}$, $\mathrm{SO}_{4}^{2-}$, and $\mathrm{NO}_{3}^{-}$.

\section{Conclusions}

In this study, the cold plasma process was employed to remove amoxicillin (AM) and TOC from real hospital wastewater. The central composite design with three factors was successfully applied to develop a mathematical model for predicting $\mathrm{AM}$ and $\mathrm{TOC}$ removal. $\mathrm{R}^{2}{ }_{\mathrm{AM}}=0.9893$ and $\mathrm{R}^{2}{ }_{\text {TOC }}=0.9716$ for the obtained polynomial model demonstrated a high correlation between observed and predicted values by the mathematical model. Under optimum values of variables (initial $\mathrm{pH}$ of 10.5 , applied voltage of 36.5 , and a reaction time of $31 \mathrm{~min}$ ), most of the AM (98.13\%) and TOC (72.41\%) was removed. Besides, the major degradation pathways of AM under coldplasma irradiation were elucidated by DFT theoretical calculations, including NBO analysis. Results revealed that cold plasma demonstrates promise for the degradation of pharmaceutical compounds from real wastewater.

\section{References}

1. AUS DER BEEK T., WEBER F.A., BERGMANN A., HICKMANN S., EBERT I., HEIN A., KÜSTER A. Pharmaceuticals in the environment - Global occurrences and perspectives. Environmental toxicology and chemistry, 35 (4), 823, 2016.

2. NGUYEN P.T.T., NGUYEN H.T., TRAN U.N.P., MANH BUI H. Removal of Antibiotics from Real Hospital Wastewater by Cold Plasma Technique. Journal of Chemistry, 9981738 1, 2021.

3. WHO W.H.O. Pharmaceuticals in drinking water Public health and environment, water, sanitation, hygiene and health. WHO, Geneva; 2011. 
4. MOHMMED E., ABDELKARIM A.M., OSHI M.A., NAEEM M. Market Survey and Assessment of the Real Demand of Amoxicillin 500mg Capsules in the Sudanese Pharmaceutical Markets. Life and Science, 2 (1), 4, 2021.

5. NAYEBI B., AYATI B. Degradation of emerging amoxicillin compound from water using the electro-Fenton process with an aluminum anode. Water Conservation Science and Engineering, 6 (1), 45, 2021.

6. FOLARIN O.S., OTITOLOJU A.A., AMAEZE N.H., SALIU J.K. Occurrence of acetaminophen, amoxicillin, diclofenac and methylparaben in Lagos and Ologe lagoons, Lagos, Nigeria. Journal of Applied Sciences and Environmental Management, 23 (12), 2143, 2019.

7. GONZÁLEZ-PÉREZ B.K., SARMA S.S.S., NANDINI S. Effects of selected pharmaceuticals (ibuprofen and amoxicillin) on the demography of Brachionus calyciflorus and Brachionus havanaensis (Rotifera). The Egyptian Journal of Aquatic Research, 42 (3), 341, 2016.

8. VERLICCHI P., ZAMBELLO E., AL AUKIDY M. Removal of pharmaceuticals by conventional wastewater treatment plants. Comprehensive analytical chemistry. 62: Elsevier; 231, 2013.

9. HA B.M. Decolorization of Suncion Red P-2B Solution by Gamma Co-60 Irradiation in the Presence of Hydrogen Peroxide. J. Adv. Oxid. Technol., 21 (1), 118, 2018.

10. NAGHAN D.J., AZARI A., MIRZAEI N., VELAYATI A., TAPOUK F.A., ADABI S., PIRSAHEB M., SHARAFI K. Parameters effecting on photocatalytic degradation of the phenol from aqueous solutions in the presence of $\mathrm{ZnO}$ nanocatalyst under irradiation of UV-C light. Bulgarian Chemical Communications, 47 14, 2015.

11. CHINNAIYAN P., THAMPI S.G., KUMAR M., BALACHANDRAN M. Photocatalytic degradation of metformin and amoxicillin in synthetic hospital wastewater: effect of classical parameters. Int. J. Environ. Sci. Technol., 16 (10), 5463, 2019.

12. HANSEN K.M.S., SPILIOTOPOULOU A., CHHETRI R.K., CASAS M.E., BESTER K., ANDERSEN H.R. Ozonation for source treatment of pharmaceuticals in hospital wastewater-ozone lifetime and required ozone dose. Chem. Eng., 290 507, 2016.

13. QIAN Y., LIU X., LI K., GAO P., CHEN J., LIU Z., ZHOU X., ZHANG Y., CHEN H., LI X. Enhanced degradation of cephalosporin antibiotics by matrix components during thermally activated persulfate oxidation process. Chem. Eng., 384 123332, 2020.

14. YEGANE BADI M., FALLAH JOKANDAN S., ESRAFILI A., YOUSEFZADEH S., AHMADI E., AZARI A., MOKHTARI S.A., REZAEI NIA S., GHOLAMI M. Optimization of advanced oxidation process based on persulfate $\left(\mathrm{Uv} / \mathrm{Na}_{2} \mathrm{~S}_{2} \mathrm{O}_{8} / \mathrm{Fe}^{2+}\right)$ for phthalic acid removal from aqueous solutions with response surface methodology. Journal of Babol University of Medical Sciences, 20 (2), 13, 2018.

15. DUY N.N., HIEU T.N., LUU T.P., THANH X.B., THUY T.D., JIANG J.J., PERNG Y.S., BOUJELBANE F., HA M.B. Removal of leucomalachite green in an aqueous solution by the electron beam process. Journal of Water Process Engineering, 101781, 2020.

16. DUY N.N., HIEU T.N., LUU T.P., CONG T.N., HUONG T.G.D., HIEN Q.N., CHEN Y.C., HIEP N.B., HIEN T.D.V., TRUC V.N., HA M.B. Degradation of tricyclazole from aqueous solution and real wastewater by electron-beam irradiation. Environmental Technology \& Innovation, 21 101315, 2021.
17. PATEL M., KUMAR R., KISHOR K., MLSNA T., PITTMAN JR C.U., MOHAN D. Pharmaceuticals of emerging concern in aquatic systems: chemistry, occurrence, effects, and removal methods. Chemical reviews, 119 (6), 3510, 2019.

18. ZEGHIOUD H., PHUONG N.T., KHEZAMI L., AMRANE A., ASSADI A.A. Review on discharge Plasma for water treatment: mechanism, reactor geometries, active species and combined processes. Journal of Water Process Engineering, 38 101664, 2020.

19. SARANGAPANI C., MISRA N.N., MILOSAVLJEVIC V., BOURKE P., O'REGAN F., CULLEN P.J. Pesticide degradation in water using atmospheric air cold plasma. Journal of Water Process Engineering, 9 225, 2016.

20. TECER L.H., GÜNDÜZ A., ATAV R., SOYSAL S., Y1LD1Z F. Investigation of the Treatment of Textile Wastewater with Cold Atmospheric Plasma Reactor (Profoks) and Reuse of Recycled Water in Reactive Dyeing Process of Cotton. Journal of Natural Fibers, 1, 2020.

21. KIM H.-J., WON C.-H., KIM H.-W. Pathogen deactivation of glow discharge cold plasma while treating organic and inorganic pollutants of slaughterhouse wastewater. Water, Air, \& Soil Pollution, 229 (7), 1, 2018.

22. SARANGAPANI C., ZIUZINA D., BEHAN P., BOEHM D., GILMORE B.F., CULLEN P.J., BOURKE P. Degradation kinetics of cold plasma-treated antibiotics and their antimicrobial activity. Scientific reports, 9 (1), 1, 2019.

23. APHA A.P.H.A. Standard methods for the examination of water and wastewater. American Public Health Association (APHA): Washington, DC, USA, 2005.

24. LIAO X., LIU D., CHEN S., YE X., DING T. Degradation of antibiotic resistance contaminants in wastewater by atmospheric cold plasma: kinetics and mechanisms. Environmental technology, 42 (1), 58, 2021.

25. MONTGOMERY D.C. Design and Analysis of Experiments, Eighth ed.;John Wiley \& Sons, Inc.: United States, pp. 2013.

26. HA M.B. Optimization of electrocoagulation of instant coffee production wastewater using the response surface methodology. Polish Journal of Chemical Technology, 19 (2), 67, 2017.

27. PANOREL I., PREIS S., KORNEV I., HATAKKA H., LOUHI-KULTANEN M. Oxidation of aqueous pharmaceuticals by pulsed corona discharge. Environmental technology, 34 (7), 923, 2013.

28. LIU Y., ZHANG H., SUN J., LIU J., SHEN X., ZHAN J., ZHANG A., OGNIER S., CAVADIAS S., LI P. Degradation of aniline in aqueous solution using nonthermal plasma generated in microbubbles. Chem. Eng., $345679,2018$.

29. ANCHIQUE L., ALCÁZAR J.J., RAMOS-HERNANDEZ A., MÉNDEZ-LÓPEZ M., MORA J.R., RANGEL N., PAZ J.L., MÁRQUEZ E. Predicting the Adsorption of Amoxicillin and Ibuprofen on Chitosan and Graphene Oxide Materials: A Density Functional Theory Study. Polymers, 13 (10), 1620, 2021.

30. BEBU A., SZABÓ L., LEOPOLD N., BERINDEAN C., DAVID L. IR, Raman, SERS and DFT study of amoxicillin. Journal of Molecular Structure, 993 (1-3), 52, 2011.

31. GAO B., WANG J., DOU M., XU C., HUANG X. Enhanced photocatalytic removal of amoxicillin with $\mathrm{Ag} /$ $\mathrm{TiO}_{2} /$ mesoporous $\mathrm{gC}_{3} \mathrm{~N}_{4}$ under visible light: property and mechanistic studies. Environmental Science and Pollution Research, 27 (7), 7025, 2020. 